\title{
Management and long-term outcome of neonatal Ebstein anomaly
}

\author{
Takeshi Shinkawa, MD, ${ }^{\text {a }}$ Anastasios C. Polimenakos, MD, ${ }^{a}$ Carlen A. Gomez-Fifer, MD, ${ }^{b}$ \\ John R. Charpie, MD, ${ }^{\mathrm{b}}$ Jennifer C. Hirsch, MD, ${ }^{\mathrm{a}}$ Eric J. Devaney, MD, ${ }^{\mathrm{a}}$ Edward L. Bove, MD, and \\ Richard G. Ohye, MD ${ }^{\mathrm{a}}$
}

Objective: The objective of this study was to review the long-term results of symptomatic patients with Ebstein anomaly in the neonatal period.

\begin{abstract}
Methods: The medical records of 40 neonates with a diagnosis of Ebstein anomaly who were admitted to our institution between January 1988 and June 2008 were retrospectively reviewed. Primary outcomes studied included patient survival and need for reintervention.
\end{abstract}

\begin{abstract}
Results: No early intervention was required in 16 of the 40 patients with a hospital survival of $94 \%(15 / 16)$ and no late mortality. The remaining 24 patients underwent surgical intervention in the neonatal period. A shunt alone was performed in 9 patients with an actuarial survival of $88.9 \%$ at 1 year and $76.2 \%$ at 5 and 10 years. For the patients undergoing intervention on the tricuspid valve, survival estimates for the 11 patients with a right ventricular exclusion procedure were $63.6 \%$ at 1,5 , and 10 years and $47.7 \%$ at 15 years compared with $25.0 \%$ at 1,5 , and 10 years for the 4 patients with tricuspid valve repair. All long-term survivors were in New York Heart Association class I or II, and only 1 patient required antiarrhythmic medication.
\end{abstract}

Conclusion: Symptomatic neonates with Ebstein anomaly requiring no intervention or shunting alone have good long-term survival. For patients needing intervention on the tricuspid valve, overall survival is lower. For these patients, right ventricular exclusion may be superior to tricuspid valve repair. (J Thorac Cardiovasc Surg 2010;139:354-8)

Ebstein anomaly is a congenital malformation involving the tricuspid valve and right ventricle $(\mathrm{RV})$. The classic features are apical displacement of the septal leaflet of the tricuspid valve with a thin atrialized portion of $\mathrm{RV}$ in addition to a malformed anterior leaflet, which may have anomalous attachments in the RV outflow tract. This anomaly has a variable clinical course. The age at presentation for patients with Ebstein anomaly is bimodal, with patients presenting as neonates or as older children and adults. For patients with a severe form of Ebstein anomaly, there is a high rate of fetal demise. ${ }^{1}$ Symptomatic neonates often are critically ill with a combination of congestive heart failure and cyanosis resulting from decreased pulmonary blood flow, tricuspid valve regurgitation, depressed RV function, and low cardiac output. ${ }^{2}$ The management of the symptomatic neonate remains challenging, ${ }^{3,4}$ and the optimal surgical intervention is controversial inasmuch as there are several operative options, including tricuspid valve repair or replacement, systemic-pulmonary artery (SP) shunt, tricuspid

\footnotetext{
From the Division of Pediatric Cardiovascular Surgery, Section of Cardiac Surgery, Department of Surgery, ${ }^{\mathrm{a}}$ and the Division of Pediatric Cardiology, Department of Pediatrics and Communicable Disease, ${ }^{\mathrm{b}}$ University of Michigan Medical School, Ann Arbor, Mich.

Disclosures: None.

Received for publication Jan 9, 2009; revisions received April 8, 2009; accepted for publication July 23, 2009; available ahead of print Sept 23, 2009.

Address for reprints: Richard G. Ohye, MD, 5144 CVC/SPC 5864, 1500 East Medical Center Dr, Ann Arbor, MI 48109-5864 (E-mail: ohye@umich.edu). 0022-5223/\$36.00

Copyright (c) 2010 by The American Association for Thoracic Surgery doi:10.1016/j.jtcvs.2009.07.062
}

valve closure with SP shunt (RV exclusion), ${ }^{5}$ and heart transplantation.

In an effort to understand the prognosis and optimal management of symptomatic neonates with Ebstein anomaly, we retrospectively reviewed this group of patients at our institution. Major outcomes studied included patient survival and need for reintervention.

\section{PATIENTS AND METHODS \\ Study Design}

Between January 1988 and June 2008, all patients less than 30 days of age admitted to the C.S. Mott Children's Hospital, University of Michigan Health Center, with Ebstein anomaly were included in this retrospective study. Patients who had other complex cardiac anomalies not classically associated with Ebstein anomaly were excluded.

Approval from the Institutional Review Board of the University of Michigan was obtained. Medical records were reviewed with regard to the initial clinical features, surgical intervention, and postoperative data. Echocardiograms conducted at admission were reviewed and the degree of tricuspid valve regurgitation and Great Ormond Street (GOS) score were assessed. The tricuspid valve regurgitation was qualitatively graded by color Doppler using a scale of 0 (none) to 4 (severe), and the GOS score was determined as a product of the combined area of the right atrium and the atrialized RV divided by the area of the trabeculated RV and left-sided chambers, as described by Celermajer and associates. ${ }^{3}$ Current follow-up data were available for $36(90 \%)$ of the 40 patients.

\section{Management Protocol and Surgical Technique}

The symptomatic neonate with Ebstein anomaly generally has cyanosis. When pulmonary blood flow is ductus-dependent, a prostaglandin infusion is administered to maintain pulmonary circulation. Complete anatomic evaluation with echocardiography is performed to assess the anatomy, particularly the presence of structural or functional RV outflow tract obstruction. 


$$
\begin{aligned}
& \text { Abbreviations and Acronyms } \\
& \qquad \begin{aligned}
\text { GOS } & =\text { Great Ormond Street } \\
\text { RV } & =\text { right ventricle (ventricular) } \\
\text { SP } & =\text { systemic-pulmonary artery }
\end{aligned}
\end{aligned}
$$

Patients with an anatomically unobstructed RV outflow tract undergo a trial of weaning from the prostaglandin infusion as the pulmonary vascular resistance falls. A trial of nitric oxide to decrease pulmonary vascular resistance may be helpful. If the wean is successful without congestive heart failure and systemic saturations are maintained at greater than approximately $75 \%$, no intervention is pursued in the neonatal period. If the wean is unsuccessful owing to excessive cyanosis alone, an SP shunt is performed. If the wean is unsuccessful owing to a combination of cyanosis and congestive heart failure, an SP shunt alone will only mimic the condition seen with prostaglandin support, and the tricuspid valve itself needs to be addressed. In this situation, either RV exclusion or tricuspid valve repair is performed.

The decision to repair the valve depends on the anatomy and the likelihood of successful repair. When repairing the tricuspid valve, we currently prefer the Carpentier "cone" technique, which consists of detaching the anterior leaflet and reattaching it to the tricuspid valve annulus. ${ }^{6}$ The atrialized portion of the $\mathrm{RV}$ is not plicated. In the $\mathrm{RV}$ exclusion procedure, the patch is fenestrated if there is associated significant RV outflow tract obstruction or atresia, and the coronary sinus is placed on either the RV side or right atrial side at the surgeon's preference, depending on the individual anatomy. The atrialized RV is not routinely plicated. In either situation, the atrial defect is kept open (Figure 1).

\section{Statistical Analysis}

Data are expressed as mean \pm standard deviation for continuous variables and as median and range for categorical variables. Among subgroups of patients, the degree of tricuspid valve regurgitation and the GOS scores were compared by the Student $t$ test. The Kaplan-Meier estimate of operative survival was computed for all operative patients and for subgroups of patients with each surgical procedure, and the survival estimates were compared with the log-rank test. Stat Mate III software (ATMS Co, Tokyo, Japan) was used for statistical analysis.

\section{RESULTS}

\section{Patient Characteristics}

All 40 patients who received a diagnosis of Ebstein anomaly before 30 days of age and were admitted to the C.S. Mott Children's Hospital during the study period were included. Eighteen patients were male and 22 patients were female. The median weight at the admission was $3.2 \mathrm{~kg}$ (range, $1.95-4.3 \mathrm{~kg}$ ). Thirty-three of the 40 patients required a prostaglandin infusion to maintain their arterial oxygen saturation. Patient characteristics are summarized in Table 1.

\section{Preoperative Echocardiogram}

The transthoracic echocardiograms from the time of admission were reviewed. The mean degree of tricuspid valve regurgitation was $2.9 \pm 1.1$ and the mean GOS score was $0.77 \pm 0.28$. Regarding the RV outflow tract, 7 patients had anatomic pulmonary atresia, 6 patients had functional pulmonary atresia (no antegrade flow through the pulmonary valve), and 7 patients had severe pulmonary stenosis (minimal antegrade flow through the pulmonary valve).

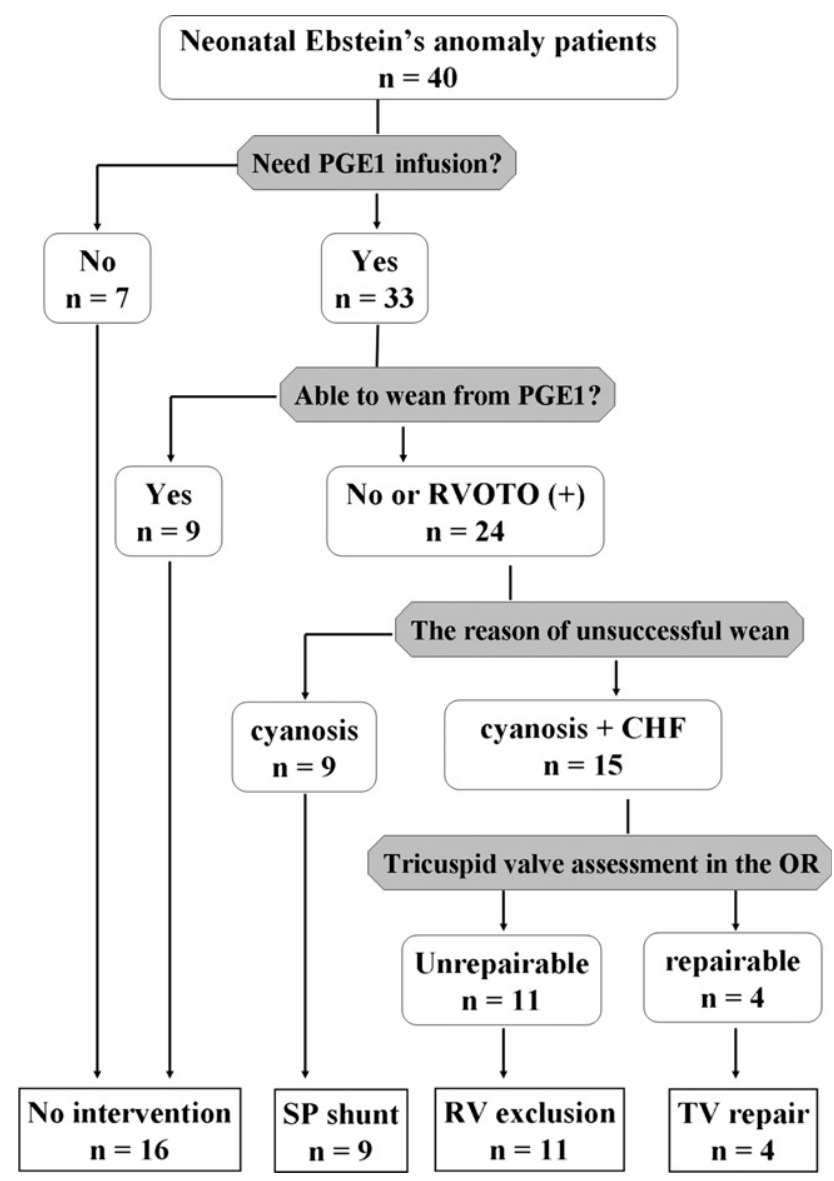

FIGURE 1. Management protocol for neonates with Ebstein anomaly. $n$ represents number of patients for each group. $C H F$, Congestive heart failure; $O R$, operating room; $P G E 1$, prostaglandin; RVOTO, right ventricular outflow tract; $S P$, systemic-pulmonary artery; $T V$, tricuspid valve; $R V$, right ventricle.

\section{Operative Interventions}

After medical stabilization, 16 patients required no intervention and 24 patients underwent surgical intervention during the neonatal period according to the criteria previously described. Among the 24 patients requiring surgical intervention, the median age at the time of operation was 6 days (range, 1-17 days) and the median weight was $3.2 \mathrm{~kg}$ (range, 2.5-4.1 kg). Eleven of the 24 patients underwent an RV exclusion procedure (tricuspid valve closure with SP shunt), 9 patients underwent an SP shunt with or without patent ductus arteriosus ligation or atrial septectomy, and 4 patients underwent a tricuspid valve repair (Figure 1). Two patients required tricuspid valve closure after an initial SP shunt, 1 valve was closed 2 days after SP shunt, and the other was closed at the time of stage II palliation (hemi-Fontan procedure).

The degree of tricuspid valve regurgitation of the patients who did not require intervention and those who underwent surgical intervention was not significantly different $(2.6 \pm$ 1.0 vs $3.0 \pm 1.1$, respectively). However, the GOS score 
TABLE 1. Patient characteristics and associated lesions

\begin{tabular}{|c|c|c|c|c|c|}
\hline & \multirow[b]{2}{*}{ All patients } & \multirow[b]{2}{*}{ No intervention } & \multicolumn{3}{|c|}{ Surgical intervention } \\
\hline & & & SP shunt & RV exclusion & TV repair \\
\hline RVOT obstruction & 20 & & 6 & & 4 \\
\hline VSD & 2 & & & & 2 \\
\hline Arrhythmia & 3 & & $1(\mathrm{SVT})$ & $2(\mathrm{WPW}, \mathrm{SVT})$ & \\
\hline Hydrops & 1 & & & 1 & \\
\hline Seizure activity & 1 & & & 1 & \\
\hline $\mathrm{Rh}$ incompatibility & 1 & 1 & & & \\
\hline Microsomal anomaly & 1 & 1 & & & \\
\hline Preoperative prostaglandin & 33 & 9 & 9 & 11 & 4 \\
\hline Preoperative inotropes & 16 & 5 & 2 & 7 & 2 \\
\hline Preoperative mechanical ventilation & 17 & 5 & 4 & 4 & 3 \\
\hline Preoperative ECMO & 3 & 1 & 2 & & 1 \\
\hline
\end{tabular}

was significantly different between the patients who did and did not require surgical intervention $(0.89 \pm 0.29$ vs $0.60 \pm$ 0.17 , respectively; $P<.01$ ). The degree of tricuspid valve regurgitation among the patients who underwent SP shunt, an RV exclusion procedure, and tricuspid valve repair was not significantly different $(2.7 \pm 1.3$ vs $3.1 \pm 0.9$ vs $3.6 \pm 0.5$, respectively). However, the GOS scores of the patients who underwent tricuspid valve repair was significantly greater than those of patients requiring only an SP shunt ( $1.15 \pm 0.28$ vs $0.73 \pm 0.27$, respectively; $P=.03$ ).

Among the 13 patients who underwent an RV exclusion procedure in the neonatal period or at the time of the hemi-Fontan procedure, 5 patients required fenestrated patch closure of the tricuspid valve because of severe RV outflow tract obstruction. The coronary sinus was situated in the RV in 9 patients and in the right atrium in 4 patients. Concomitant SP shunt was performed in all patients (modified Blalock-Taussig shunt in 7 patients and central shunt in 6), 3.5 or $4 \mathrm{~mm}$ in size, based on body weight.

Among the 4 patients who underwent tricuspid valve repair, all required a pulmonary valvotomy or RV outflow tract reconstruction, and 2 patients required an additional SP shunt to maintain their arterial oxygen saturation.

\section{Outcomes}

Among the 16 patients who received no intervention, 15 patients survived the neonatal period and 2 patients were lost to follow-up at a mean interval of $6.8 \pm 6.1$ years. Three patients required tricuspid valve repair later in life (at 4, 8, and 13 years of age), and 1 patient required repair of coarctation of the aorta at 1 year of age. Among the 24 neonates undergoing an operation, there were 6 hospital deaths, 3 patients who underwent an RV exclusion procedure and 3 patients who underwent a tricuspid valve repair. There were 4 late deaths among the 18 early survivors at a mean follow-up of $7.2 \pm 5.1$ years. All long-term survivors are in New York Heart Association class I or II.
Subdividing the patients requiring intervention by procedure revealed that among the 11 patients who underwent RV exclusion, $8(73 \%)$ survived to discharge. One patient suddenly died at home 3 months after the operation of an unknown cause, 7 (63\%) patients have had completion of the Fontan procedure, and 1 patient died 11 years after the Fontan procedure of severe systemic infection, including sepsis, empyema, and endocarditis.

All 9 patients who underwent an SP shunt survived to discharge. One patient required extracorporeal membrane oxygenation support and tricuspid valve closure early postoperatively. Two patients have had completion of a Fontan procedure, 1 patient underwent tricuspid valve replacement and RV-pulmonary artery conduit, 1 patient underwent 1 -and-one-half ventricle repair, and 1 patient is awaiting a Fontan procedure after tricuspid valve closure at the time of a stage II procedure. There were 2 late deaths; 1 patient died at the time of stage II palliation because of hypoxemia and low cardiac output syndrome, and 1 patient died at the time of Fontan procedure because of severe ventricular dysfunction. Two patients were lost to follow-up.

Among 4 patients who underwent tricuspid valve repair, there were 3 hospital deaths; the fourth patient survived and is doing well without reoperation for 12.5 years (Figure 2).

The overall survival estimate for all patients undergoing surgical intervention was $66.7 \%$ at 1 year, $62.2 \%$ at 5 and 10 years, and $51.9 \%$ at 15 years. The survival estimates for patients who underwent an RV exclusion procedure were $63.6 \%$ at 1,5 , and 10 years and $47.7 \%$ at 15 years. For the patients who underwent an SP shunt, the actuarial survival was $88.9 \%$ at 1 year and $76.2 \%$ at 5 and 10 years. For patients who underwent a tricuspid valve repair, the actuarial survival was $25.0 \%$ at 1,5 , and 10 years (Figure 3 ). There was a significant statistical difference in the survival estimates between the patients with an SP shunt and those with tricuspid valve repair (log-rank test, $P=.019)$. 


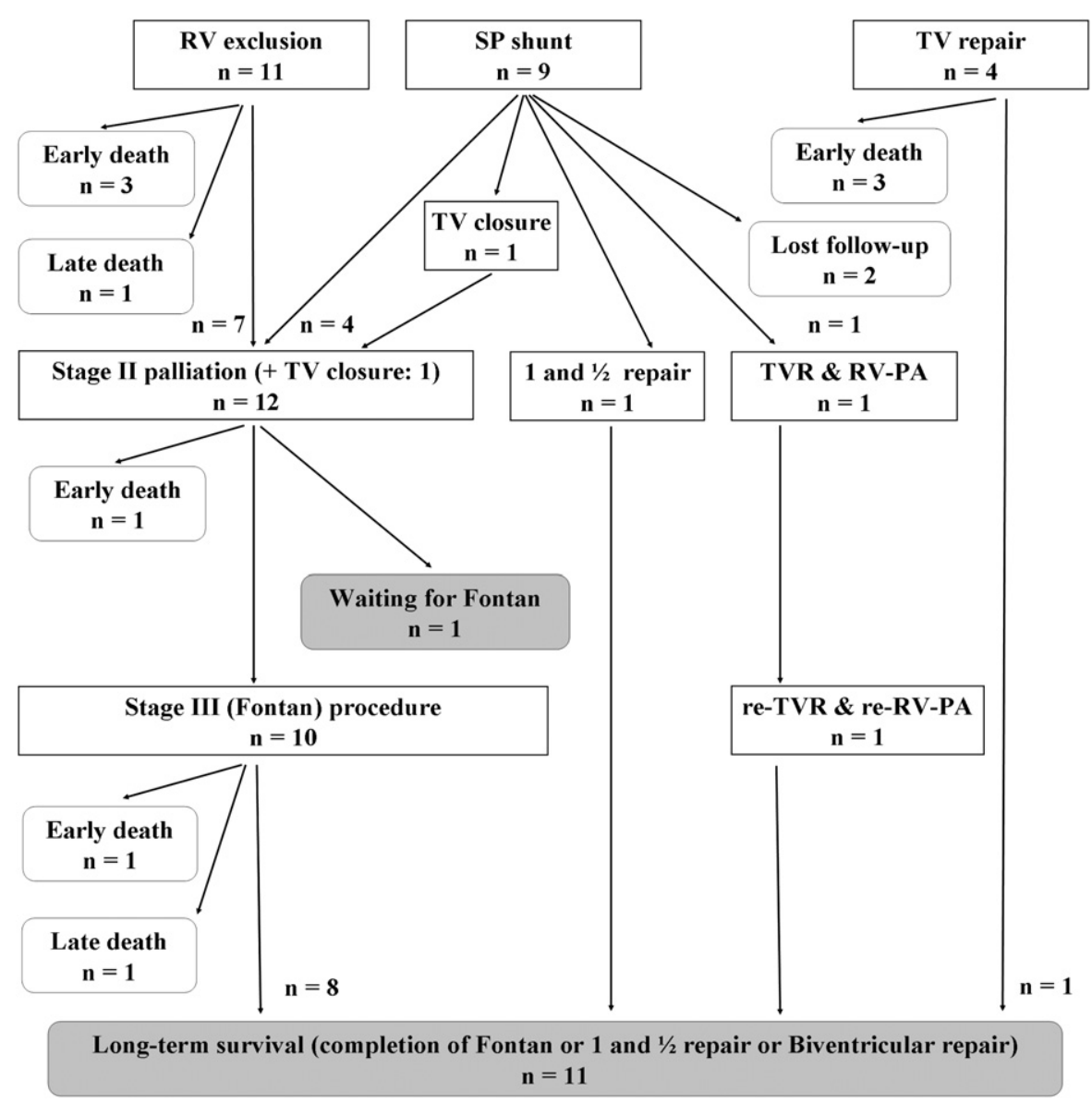

FIGURE 2. Postoperative clinical outcome for each procedure. $n$ represents number of patients for each group. $R V$, Right ventricle; $R V-P A$, right ventriclepulmonary artery conduit; $S P$, systemic-pulmonary artery; $T V$, tricuspid valve; $T V R$, tricuspid valve replacement.

\section{DISCUSSION}

Management of the symptomatic neonate with Ebstein anomaly has been controversial and challenging. Some neonates with this anomaly can be successfully managed without intervention and may undergo tricuspid valve repair later in life, but others can have severe cyanosis with or without congestive heart failure requiring early surgical intervention. Historically, the neonatal mortality for this anomaly has been high. However, recent surgical interventions to improve early survival have been successful., ${ }^{3,4}$

In the current study, $40 \%$ of the symptomatic neonates with Ebstein anomaly required no immediate surgical intervention. The overall hospital survival for this group was excellent at $94 \%(15 / 16)$ with no late deaths. To date, only 3 of these patients have required tricuspid valve repair later in life and all remain in good health. It would seem intuitively correct that the patients not requiring intervention would have a milder form of the disease. Indeed, even though we were unable to detect a difference in the degree of tricuspid regurgitation between groups requiring surgical intervention or not, there was a significant difference in the GOS score. Although the GOS score may be a surrogate for severity of dis- ease, we would not advocate for either GOS score or degree of tricuspid regurgitation to be used as the sole determinant for the need for surgical intervention. This decision is based more appropriately on the patient's ability to tolerate weaning from a prostaglandin infusion.

Prostaglandin weaning will fail because of unacceptable cyanosis in a subgroup of patients, and they will require intervention in the neonatal period. When receiving prostaglandin, if the patient has an acceptable systemic oxygen saturation without congestive heart failure, an SP shunt is a reasonable option. The use of an SP shunt alone allows for future options, including Fontan, one-and-one-half ventricle repair, and biventricular repair. The results of SP shunt alone were good, with an actuarial survival of $88.9 \%$ at 1 year and $76.2 \%$ at 5 and 10 years.

For patients with both cyanosis and congestive heart failure while receiving prostaglandin, the tricuspid valve will need to be addressed. The options include tricuspid valve repair or replacement and RV exclusion. Tricuspid valve repair is challenging in the neonate because of the complex anatomy and fragile neonatal valve tissue. More important, this anomaly is not isolated to the tricuspid valve. Rather, 


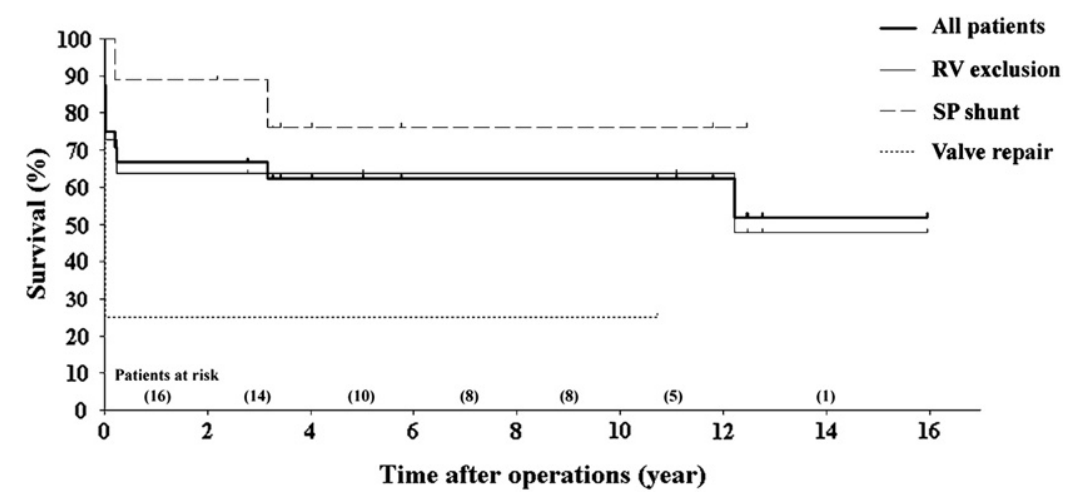

FIGURE 3. Kaplan-Meier estimates of operative survival. Thick solid line, All operative patients; thin solid line, right ventricular (RV) exclusion procedure; wide dotted line, systemic\&pulmonary artery (SP) shunt; narrow dotted line, tricuspid valve repair.

it involves the entire right heart, including varying degrees of diminished RV function and volume, in addition to RV outflow tract obstruction. Although excellent midterm results of tricuspid valve repair for neonatal Ebstein anomaly have been reported, these results are institution-dependent, and few institutions have been able to duplicate these results for tricuspid valve repair. ${ }^{8,9}$ Our outcomes for tricuspid valve repair in the neonatal period have been disappointing, with only 1 of 4 neonates surviving to discharge. The remaining 3 patients could not be weaned from cardiopulmonary bypass after tricuspid valve repair owing to severe cyanosis and hypotension. The intraoperative transesophageal echocardiogram suggested that the RV could not generate adequate pulmonary blood flow even with a more competent tricuspid valve and nonrestrictive RV outflow tract. We have largely abandoned neonatal tricuspid valve repair, except in cases of favorable tricuspid valve, RV, and RV outflow tract anatomy.

The other option for these neonates is RV exclusion. Since Starnes and his colleagues ${ }^{5}$ published their early experience with RV exclusion in 1991, this procedure has been widely used for symptomatic neonates who have both cyanosis and congestive heart failure. ${ }^{10}$ This procedure can reduce right heart dilatation by excluding the RV from the circulation; moreover, it can improve left ventricular dimension and function. ${ }^{11}$ The technique applied at our institution includes selective patch fenestration depending on the degree of RV outflow tract obstruction, placement of the coronary sinus on either the atrial or ventricular side of the patch depending on surgeon preference, and no plication of the atrialized portion of the $\mathrm{RV}$. The early survival of patients with $\mathrm{RV}$ exclusion in our population was $72.7 \%$, which is similar to other reported series. ${ }^{8,10}$

Ebstein anomaly represents a spectrum of disease with a variable need for surgical intervention. Optimally, neonates with symptomatic Ebstein anomaly can be weaned successfully from prostaglandin and discharged without the need for intervention. For those patients who cannot be weaned from prostaglandin, an SP shunt alone can be used if congestive heart failure is absent. For patients with both cyanosis and congestive heart failure necessitating tricuspid valve intervention in the newborn period, our data would suggest that RV exclusion (tricuspid valve closure with an SP shunt) results in the most favorable outcome. Although tricuspid valve repair allows for biventricular anatomy and remains an important part of the surgeon's armamentarium for older children, it is best reserved for those neonates with the most favorable anatomy based on preoperative and intraoperative assessment.

\section{References}

1. Hornberger LK, Sahn DJ, Kleinman CS, Copel JA, Reed KL. Tricuspid valve disease with significant tricuspid insufficiency in the fetus: diagnosis and outcome. J Am Coll Cardiol. 1991;17:167-73.

2. Celermajer DS, Dodd SM, Greenwald SE, Wyse RK, Deanfield JE. Morbid anatomy in neonates with Ebstein's anomaly of the tricuspid valve: pathophysiologic and clinical implications. J Am Coll Cardiol. 1992;19:1049-53.

3. Celermajer DS, Cullen S, Sullivan ID, Spiegelhalter DJ, Wyse RK, Deanfield JE. Outcome in neonates with Ebstein's anomaly. J Am Coll Cardiol. 1992;19: 1041-6.

4. Gentles TL, Calder AL, Clarkson PM, Neutze JM. Predictors of long-term survival with Ebstein's anomaly of the tricuspid valve. Am J Cardiol. 1992;69: 377-81.

5. Starnes VA, Pitlick PT, Bernstein D, Griffin ML, Choy M, Shumway NE. Ebstein's anomaly appearing in the neonate: a new surgical approach. J Thorac Cardiovasc Surg. 1991;101:1082-7.

6. Carpentier A, Chauvaud S, Macé L, Relland J, Mihaileanu S, Marino JP, et al. A new reconstructive operation for Ebstein's anomaly of the tricuspid valve. $J$ Thorac Cardiovasc Surg. 1988;96:92-101.

7. Sarris GE, Giannopoulos NM, Tsoutsinos AJ, Chatzis AK, Kirvassilis G, Brawn WJ, et al. Results of surgery for Ebstein's anomaly: a multicenter study from the European Congenital Heart Surgeons Association. J Thorac Cardiovasc Surg. 2006;132:50-7.

8. Knott-Craig CJ, Goldberg SP, Overhold ED, Colvin EV, Kirklin JK. Repair of neonates and young infants with Ebstein's anomaly and related disorders. Ann Thorac Surg. 2007;84:587-93.

9. Jaquiss RDB, Imamura M. Management of Ebstein's anomaly and pure tricuspid insufficiency in the neonate. S emin Thorac Cardiovasc Surg. 2007;19: 258-63.

10. Reemtsen BL, Polimenakos AC, Fagan BT, Wells WJ, Starnes VA. Fate of the right ventricle after fenestrated right ventricular exclusion for severe neonatal Ebstein anomaly. J Thorac Cardiovasc Surg. 2006;132:1285-90.

11. Reemtsen BL, Fagan BT, Wells WJ, Starnes VA. Current surgical therapy for Ebstein anomaly in neonates. J Thorac Cardiovasc Surg. 2007;134:1406-10. 